\title{
Solution to the osmium density challenge
}

John W. Arblaster

(C) Springer-Verlag Berlin Heidelberg 2014

What would the atomic weight of osmium have to change to in order for iridium to become the densest metal [1]? Iridium becomes denser than osmium when $\rho(\mathrm{Ir})>\rho(\mathrm{Os})$. The density of iridium is $\rho(\mathrm{Ir})=22.562 \pm 0.011 \mathrm{~g} / \mathrm{cm}^{3}$ and the density of osmium is $\rho(\mathrm{Os})=22.589 \pm 0.005 \mathrm{~g} / \mathrm{cm}^{3}$. Comparing two numbers that have associated uncertainties is not a trivial task, but in the most simplistic approach the density of osmium has to be less than $22.562 \mathrm{~g} / \mathrm{cm}^{3}$ in order for iridium to become the "densest metal" at normal conditions. The density and the atomic weight are directly related:

$\rho(\mathrm{Os})_{\text {new }} / \rho(\mathrm{Os})_{\text {old }}=A_{\mathrm{r}}(\mathrm{Os})_{\text {new }} / A_{\mathrm{r}}(\mathrm{Os})_{\text {old }}$.

The value $\rho(\mathrm{Os})=22.589 \mathrm{~g} / \mathrm{cm}^{3}$ derives from the atomic weight $A_{\mathrm{r}}(\mathrm{Os})=190.23(3)$. Consequently,

$A_{\mathrm{r}}(\mathrm{Os})_{\text {new }}=190.23 \times\left(22.562 \mathrm{~g} / \mathrm{cm}^{3}\right) /\left(22.589 \mathrm{~g} / \mathrm{cm}^{3}\right)=190.00$.

This article is the solution to the Analytical Challenge to be found at http://dx.doi.org/10.1007/s00216-014-7839-z.

J. W. Arblaster $(\bowtie)$

Wombourne, Staffordshire, UK

e-mail: jwarblaster@yahoo.co.uk
Hence, iridium becomes denser than osmium at normal conditions when $A_{\mathrm{r}}(\mathrm{Os})<190.00$. Is it likely that the standard atomic weight of osmium might be revised down from 190.23 to 190.00 ? Although wide variations in the atomic weight of osmium were originally obtained with chemical determinations, experience with modern mass spectrometric determinations of atomic weight indicates that it is unlikely that a revised value would differ from the current value by more than a very small amount.

\section{References}

1. Arblaster JW (2014) Platin Met Rev 39:164 